\title{
Impact of surgery for stage IA non-small- cell lung cancer on patient quality of life
}

\author{
Rebecca M Schwartz, PhD, ${ }^{a}$ Rowena Yip, MPH, Ingram Olkin, $\mathrm{PhD},{ }^{\mathrm{c}}$ Daniel Sikavi, a \\ Emanuela Taioli, $\mathrm{MD}, \mathrm{PhD},{ }^{\mathrm{d}}$ and Claudia Henschke, $\mathrm{MD}, \mathrm{PhD},{ }^{\mathrm{b}}$ for the International Early \\ Lung Cancer Action Program (I-ELCAP) investigators
}

${ }^{a}$ Department of Occupational Medicine, Epidemiology and Prevention, North Shore-LIJ School of Medicine, Great Neck, New York; ' Department of Radiology, Icahn School of Medicine at Mount Sinai, New York; 'Department of Statistics, Stanford University, Stanford, California; and dDepartment of Population Health Science and Policy and Institute for Translational Epidemiology, Icahn School of Medicine at Mount Sinai, New York

Background There is a paucity of literature comparing quality of life (QoL) before and after surgery in stage IA lung cancer, where surgical resection is the recommended curative treatment.

Objective To assess the impact of surgery on physical and mental health-related QoL in patients with stage IA lung cancer treated with surgical resection.

Methods Participants in the I-ELCAP cohort who were diagnosed with their first primary pathologic stage IA non-small-cell lung cancer, underwent surgery, and provided follow-up information on QoL 1 year later were included in the present analysis ( $\mathrm{N}=$ 107). QoL information was collected using the SF-12 (12-item Short Form Health Survey), which generates 2 component scores related to mental health and physical health.

Results Statistical analyses indicated that physical health QoL was significantly worsened from before surgery to after surgery, whereas mental health QoL marginally improved from before to after surgery. Physical health QoL worsened for women from baseline to follow-up, but not for men. Only lobectomy (not limited resection) had an impact on QoL from before to after surgery. Limitations Results are considered preliminary given the small sample size and multiple comparisons.

Conclusions The current study findings have implications for lung cancer health care professionals in regard to how they can most effectively present the possible impact of surgery on quality of life to this subset of patients in which disease has not yet significantly progressed.

Funding/sponsorship Gift from Sonia Lasry Gardner, in memory of her father, Moise Lasry.

$\mathrm{T}$ here is a growing body of literature that highlights the importance of health-related quality of life (HRQoL) when evaluating the efficacy of cancer treatments and cancer outcomes. $^{1-3}$ Although there are a number of definitions for HRQoL, there is broad agreement that it is the effect on a patient's well-being of a medical condition and/or of the therapy administered to treat that condition. ${ }^{3-5}$ Consequently, HRQoL is a subjective, multidimensional construct that encompasses physical, social, cognitive, psychological, and somatosensory domains, ${ }^{2,6-8}$

Compared with other cancers, patients with lung cancer experience especially high symptom burdens, multiple comorbidities, and numerous emotional concerns. ${ }^{9-15}$ Although surgery is the primary course of treatment for early stage non-small-cell lung cancer (NSCLC), ${ }^{16}$ there has been limited research examining HRQoL in oncology and thoracic sur- gery. ${ }^{17,18}$ Given the high burden of disease and lack of research, evaluations of HRQoL after treatment for lung cancer are needed.

The literature is mixed regarding the impact of surgery for lung cancer on physical and mental HRQoL. Some study findings suggest that a low baseline HRQoL is predictive of poorer survival in lung cancer patients, ${ }^{1,2,17,19-26}$ and HRQoL is reported to be low in lung cancer survivors compared with the general population and populations at risk for lung cancer. ${ }^{27,28}$ However, other studies contradict those findings, reporting that baseline HRQoL scores have no significant effect on overall survival or recurrence-free survival. ${ }^{29,30}$ Numerous studies have found a decrease in post-operative HRQoL, compared with pre-operative levels..$^{27,31-36}$ Several of these studies indicate that the decrease in QoL is a short-term event, and the scores return to pre-operative levels within 3 to 9 months after

Accepted for publication November 6, 2015. Correspondence: Rebecca M Schwartz, PhD; rschwartz3@nshs.edu. Disclosures: The authors have no disclosures. JCSO 2016;14:37-44. (C2016 Frontline Medical Communications. DOI 10.12788/jicso.0205. 
surgery ${ }^{37,38}$ one study found that physical QoL surpassed baseline levels 1 year after surgery. ${ }^{31}$ However, others

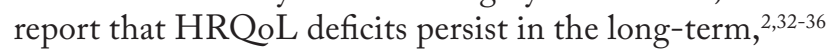
with some reporting stable deficits that last throughout survivorship. ${ }^{2,35,36}$ These permanent impairments to physical and mental HRQoL include effects on sleeping, normal daily activities, sexual activity, mental function, depression, distress, and vitality, while the most severe impairments to physical HRQoL are impaired mobility and breathing..$^{28,35}$

Changes in HRQoL among lung patients who undergo surgery is also dependent on the extent of surgery, with less invasive approaches being associated with better post-surgery physical QoL scores, ${ }^{30,39,36}$ and fastest return to presurgical values, ${ }^{30}$ although a recent study suggested that QoL did not differ between bilobectomy and lobectomy patients. ${ }^{39}$ Furthermore, patients who receive post-surgical rehabilitation and supportive care services have been found to have improved HRQoL after surgery. ${ }^{40,41}$

Despite the body of literature on the impact of surgery on HRQoL in patients with lung cancer who undergo various treatment options, and the few studies ${ }^{28,39}$ that analyzed QoL exclusively after surgery in early-stage lung cancer, there is a paucity of literature comparing QoL before and after surgery in stage IA lung cancer, for which surgical resection is the recommended curative treatment. ${ }^{42}$ One study involving patients with stage I lung cancer who were randomized to either sublobar resection or sublobar resection with brachytherapy, found that there was no significant difference between the 2 treatment groups in the percentage of change (pre-post surgery) in QoL score. ${ }^{30}$ This research did find, however, that greater improvement in physical health QoL was more likely among patients who underwent VATS (videoassisted thoracic surgery) compared with those who had thoracotomy. ${ }^{29}$ The study did not analyze the impact of surgery on mental compared with physical health QoL. Ostroff and colleagues found that early-stage lung cancer survivors who had undergone surgery 1-6 years prior had lower physical health QoL scores compared with a screening sample, but there was no difference between the 2 samples on mental health QoL scores. ${ }^{27}$ When compared with healthy controls, however, mental and physical HRQoL has been shown to be significantly worse among post-lobectomy lung cancer patients. ${ }^{43}$

It is imperative that the effects of surgery and of the type of surgical approach (lobectomy versus limited resection) on HRQoL are understood in surgically treated stage I lung cancer in order to guide the treatment decision-making process. The current study assesses for the first time the impact of surgery on physical and mental health-related quality of life in patients with stage IA lung cancer diagnosed by computerized-tomography (CT) screening and treated with surgical resection, and attempts to understand whether there is differential impact on HRQoL based on type of surgery (limited resection vs lobectomy). Further, in lung cancer specifically, studies have noted differences between men and women in terms of HRQoL outcomes and overall survival, with women usually faring worse than men on all outcomes, ${ }^{29,44-47}$ although one study found that men fared worse on physical health QoL than did women, ${ }^{47}$ and another found no differences in QoL based on gender. ${ }^{48}$ As such, the current study also aims to delineate any differences in outcomes by sex, and it is hypothesized that women will likely have worse HRQoL outcomes after surgery than do men.

\section{Methods}

This report draws from the database of the diagnosed cases of NSCLC identified as a result of CT screening in the International Early Lung Cancer Action Program (I-ELCAP) cohort. The screenings were performed under an IRB-approved, HIPAA-compliant common protocol at each of the participating institutions from 2001 (when the SF-12 [12-item Short Form Health Survey] HRQoL measure started to be collected) to 2014 on smokers, never-smokers, and participants with occupational exposure to airborne carcinogens or exposure to secondhand smoke who were 40 years or older. ${ }^{49}$ Consent was obtained from all of the participants at the time of enrollment. They were interviewed to obtain information on relevant demographics, occupational history, smoking habits, and comorbidities. For the purposes of this study, only participants diagnosed with their first primary pathologic stage IA NSCLC who underwent surgery and provided follow-up SF-12 HRQoL information 1 year later (range, 7-18 months) were included in the present analysis. This time interval corresponds to the I-ELCAP screening clinical regimen for repeat CT scans. Staging classification for lung cancer was made centrally based on the American Joint Committee on Cancer Staging Manual (6th ed), with 1 exception. Cases of multiple adenocarcinomas ( $<30 \mathrm{~mm}$ in diameter) without lymph node metastases were classified as synchronous primaries and considered to be stage IA. ${ }^{6,7}$

QoL information was collected using a standard SF-12 form, a shorter version of the SF-36 questionnaire..$^{50}$ The SF-12 has been widely used and validated with samples of surgical patients. ${ }^{51,52}$ It assesses 8 domains of health: physical functioning, role limitations due to physical health, bodily pain, general health perceptions, vitality, social functioning, role limitations due to emotional problems, and mental health. The SF-12 was used to calculate 2 component scores, the Physical Component Summary Score (PCS) and the Mental Component Summary Score (MCS). Scores for MCS and PCS range from 0-100 (worst to best HRQoL). The PCS is a combination of SF-12 items that focus on participants' perceptions of their 
general health, mobility, limitations due to physical problems, and limitations in work/productivity due to physical problems and pain. Similarly, the MCS focuses on participants' experiences of symptoms of depression and anxiety, difficulties with social activity, and amount accomplished due to emotional difficulties. The SF-12 had good reliability in the present sample yielding a Cronbach's alpha of 0.85 at baseline and 0.90 at follow-up.

\section{Statistical analysis}

Continuous variables are presented as means and standard deviations, categorical variables as percentages. Univariate and multivariate analyses were performed to examine the difference in physical (PCS) and mental (MCS) health component scores of the SF-12 before and after surgery using the paired $t$ test and analysis of variance tests. All statistical analyses were performed using SAS version 9.2 (SAS Institute Inc, Cary, NC). Covariates included age, education, ethnicity, gender, current smoking status and presence of comorbid conditions (eg, liver disease, asthma, diabetes) as these are often associated with lung cancer QoL outcomes in the literature. ${ }^{48,53}$

\section{Results}

There were 107 participants (54 women, 53 men) who matched the inclusion criteria and had an SF-12 questionnaire completed at baseline CT screening and at 1-year follow-up after surgery for pathologic stage IA non-smallcell lung cancer (Table 1). Their mean age was 63 years (SD, 8.1; range, 45-83); 83 patients had lobectomy and 24 had sublobar resection. Average time of follow-up was 11 months after surgery (SD, 2.3 months; range, 7-18 months after surgery).

\section{Changes in quality of life after surgery}

On baseline screening CT, average PCS and MCS scores were 49.0 (SD, 6.9) and 52.2 (SD, 9.4), respectively. Mean post-surgery PCS was 46.8 (SD, 9.0) and MCS was 54.0 (SD, 1.8). There was a statistically significant decrease in PCS from baseline to post-surgery follow-up (-2.2; 95\% confidence interval [CI], -3.64 and -0.78); whereas MCS did not change significantly from baseline to post-surgery follow-up.

\section{Effect of type of surgery on PCS}

There was no statistically significant difference in post-surgical PCS among patients who underwent limited resection (Table 2), but there was a significant decrease in PCS score among those who underwent lobectomy $(-3.1 ; 95 \%$ CI, -4.69 and-1.42). At multivariate analysis, adjusting for sex, age, ethnicity, education, current smoking status and presence of comorbid conditions, the mean PCS at baseline and follow-up did not vary by type of surgery. The difference between baseline and follow-up was statistically

\begin{tabular}{|c|c|c|}
\hline Variable & n (\%) & Mean (SD) \\
\hline Age, y & - & $62.8(8.1)$ \\
\hline \multicolumn{3}{|l|}{ Sex } \\
\hline Women & $54(50)$ & - \\
\hline Men & $53(50)$ & - \\
\hline White & 95 (89) & - \\
\hline College education & $50(47)$ & - \\
\hline Smoking status (baseline) & & - \\
\hline Never-smoker & $1(1)$ & - \\
\hline Former smoker & $55(51)$ & - \\
\hline Current smoker & $51(48)$ & - \\
\hline Pack-years (among smokers) & - & $50.1(24.4)$ \\
\hline Lesion size before resection, $\mathrm{mm}$ & - & $14.2(6.0)$ \\
\hline \multicolumn{3}{|l|}{ Tumor pathology size, mm } \\
\hline $1-10$ & 37 (35) & - \\
\hline $11-20$ & $56(52)$ & - \\
\hline $21-30$ & $14(13)$ & - \\
\hline \multicolumn{3}{|l|}{ Lesion location } \\
\hline LLL & $13(12)$ & - \\
\hline LUL & $27(25)$ & - \\
\hline RLL & 19 (18) & - \\
\hline RML & $2(2)$ & - \\
\hline RUL & $46(43)$ & - \\
\hline
\end{tabular}

Type of surgery

Wedge resection

Segmentectomy

Lobectomy

Bilobectomy

Type of resection

Limited

Lobectomy

$83(78)$

Baseline SF-1 2

Mental health component

- $\quad 52.2(9.4)$

Physical health component

- $\quad 49.0(6.9)$

Length of follow-up, mo.

$-$

$11.3(2.3)$

Smoking status (follow-up)
Former smoker
Current smoker

92 (86)

$15(14)$

At least 1 comorbid condition

Yes

77 (72)

No

30 (28)

LLL, left lower lobe; LUL, left upper lobe; RLL, right lower lobe; RML, right middle lobe; RUL, right upper lobe; SF-12, 12 -item Short Form Health Survey 


\begin{tabular}{|c|c|c|c|c|}
\hline \multirow[b]{2}{*}{ Score } & \multirow{2}{*}{$\begin{array}{l}\text { Limited resection, } \\
\text { mean (SD) } \\
\text { [95\% Cl for mean] }\end{array}$} & \multirow{2}{*}{$\begin{array}{c}\text { Lobectomy, } \\
\text { mean (SD) } \\
{[95 \% \text { Cl for mean] }}\end{array}$} & \multicolumn{2}{|c|}{$\begin{array}{l}\text { Limited vs lobectomy, parameter estimates } \\
\qquad(95 \% \mathrm{Cl}) \text { [Limited = 1] }\end{array}$} \\
\hline & & & Unadjusteda & Adjustedb \\
\hline \multicolumn{5}{|l|}{ PCS } \\
\hline Baseline & $49.0(7.4)$ & $49.0(6.8)$ & $0.00(-3.19,3.19)$ & $0.42(-2.89,3.73)$ \\
\hline Follow-up & 49.7 (7.7) & $46.0(9.2)$ & $3.78(-0.32,7.88)$ & $4.28(0.21,8.36)$ \\
\hline $\begin{array}{l}\text { Difference } \\
\text { (follow-up baseline) }\end{array}$ & $\begin{array}{c}0.7(6.6) \\
{[-2.07,3.50]}\end{array}$ & $\begin{array}{c}-3.1 \quad(7.5) \\
{[-4.69,-1.42]}\end{array}$ & $3.77(0.42,7.13)$ & $3.86(0.48,7.24)$ \\
\hline \multicolumn{5}{|l|}{ MCS } \\
\hline Baseline & $51.3(12.8)$ & $52.5(8.2)$ & $-1.16(-5.49,3.17)$ & $-0.73(-5.09,3.62)$ \\
\hline Follow-up & $52.2(10.0)$ & $54.5(9.2)$ & $-2.27(-6.57,2.04)$ & $-2.26(-6.63,2.11)$ \\
\hline $\begin{array}{l}\text { Difference } \\
\text { (follow-up baseline) }\end{array}$ & $\begin{array}{c}0.9(1) \\
{[-4.01,5)} \\
-8.85]\end{array}$ & $\begin{array}{c}2.0(8.8) \\
{[0.10,3.95]}\end{array}$ & $-1.10(-5.48,3.27)$ & $-1.52(-5.98,2.89)$ \\
\hline
\end{tabular}

TABLE 3 SF-12 quality-of-life scores before and after surgery, overall and by sex ( $N=107)$

\begin{tabular}{|c|c|c|c|c|c|}
\hline \multirow[b]{2}{*}{ Score } & \multirow{2}{*}{$\begin{array}{l}\text { All, mean (SD) } \\
\text { [95\% Cl for } \\
\text { mean] }\end{array}$} & \multirow{2}{*}{$\begin{array}{c}\text { Men, mean (SD) } \\
{[95 \% \mathrm{CI} \text { for }} \\
\text { mean }]\end{array}$} & \multirow{2}{*}{$\begin{array}{c}\text { Women, } \\
\text { mean (SD) } \\
{[95 \% \text { Cl for mean] }}\end{array}$} & \multicolumn{2}{|c|}{$\begin{array}{l}\text { Men vs women, parameter estimates } \\
(95 \% \mathrm{Cl})\end{array}$} \\
\hline & & & & Unadjusteda & Adjustedb \\
\hline \multicolumn{6}{|l|}{ PCS } \\
\hline Baseline & $49.0(6.9)$ & $49.4(6.6)$ & $48.6(7.2)$ & $0.80(-1.86,3.46)$ & $1.34(-1.58,3.85)$ \\
\hline Follow-up & $46.8(9.0)$ & $47.5(8.4)$ & $46.1(9.6)$ & $1.34(-2.13,4.81)$ & $1.75(-1.65,5.16)$ \\
\hline $\begin{array}{l}\text { Difference } \\
\text { (follow-up baseline) }\end{array}$ & $\begin{array}{c}-2.2(7.5) \\
{[-3.64,-0.78]}\end{array}$ & $\begin{array}{c}-1.9(7.5) \\
{[-4.01,0.13]}\end{array}$ & $\begin{array}{c}-2.5(7.5) \\
{[-4.51,-0.44]}\end{array}$ & $0.54(-2.33,3.41)$ & $0.62(-2.22,3.45)$ \\
\hline \multicolumn{6}{|l|}{ MCS } \\
\hline Baseline & $52.2(9.4)$ & $53.8(9.3)$ & $50.7(9.3)$ & $3.14(-0.43,6.70)$ & $3.16(-0.40,6.73)$ \\
\hline Follow-up & $54.0(9.4)$ & $56.5(9.6)$ & 52.5 (8.9) & $3.03(-0.53,6.60)$ & $3.55(-0.05,7.14)$ \\
\hline $\begin{array}{l}\text { Difference } \\
\text { (follow-up baseline) }\end{array}$ & $\begin{array}{c}1.8(9.5) \\
{[-0.04,3.59]}\end{array}$ & $\begin{array}{c}1.7(8.2) \\
{[-0.53,3.98]}\end{array}$ & $\begin{array}{c}1.8(10.7) \\
{[-1.09,4.75]}\end{array}$ & $-0.11(-3.76,3.55)$ & $0.38(-3.24,4.00)$ \\
\hline
\end{tabular}

significant (+3.86; 95\% CI, 0.48 and 7.24) between the 2 types of surgery, although the confidence interval was wide.

\section{Effect of type of surgery on MCS}

MCS was statistically significantly improved after lobectomy $(+2.0$; 95\% CI, 0.10 and 3.95), but not after limited resection (Table 2). At multivariate analysis, adjusting for sex, age, ethnicity, education, current smoking status and presence of comorbid conditions, the mean MCS at baseline), the mean MCS at follow-up and the difference between baseline and follow-up were not significantly different according to type of surgery.

\section{Effect of sex}

A decrease in PCS was observed in both men $(-1.9 ; 95 \%$ CI, -4.01 and 0.13$)$ and women $(-2.5$; 95\% CI: -4.51 and 
-.44) after surgery, but the change was statistically significant only among women (Table 3). MCS did not significantly change from baseline to after surgery among men or women. After adjustment for age, ethnicity education, current smoking status, and presence of comorbid conditions, no differences between men and women were observed at baseline and after surgery for both PCS and MCS.

\section{Sensitivity analysis}

To eliminate the concerns about the use of a relatively wide follow-up interval (7-18 months), which is dictated by the clinical follow-up setting of the I-ELCAP study, the analyses were repeated using a narrower follow-up interval of 9-15 months after surgery (85 patients). Patients' characteristics and the direction of the results were consistent with results obtained with the wider 7-18 months interval.

\section{Discussion}

The current study is one of the first to examine the impact of surgery on both mental health and physical health quality of life among early-stage (1A) lung cancer survivors who underwent surgery as curative treatment. About a year after surgery physical health quality of life was significantly poorer than before surgery. This is consistent with other findings in more advanced lung cancers, which have indicated that physical QoL was significantly worsened after surgery. When sex is considered, the associations become more nuanced. Results indicated that mental health QoL was not significantly impacted by surgery, but that physical health QoL significantly worsened for women from baseline to follow-up, but this same effect was not observed in men. This seems to imply that women who have lung cancer surgery are at greater risk than are men for experiencing post-surgical difficulties with physical functioning. These findings are consistent with research involving other types of oncologic surgery in that women tend to have worse physical and mental health outcomes after surgery. ${ }^{54,55}$ The differences in follow-up MCS scores between men and women approached statistical significance $(P=.05)$, therefore it's possible that with an appropriately larger sample size, a significant difference would have been observed in mental health QoL.

When type of surgery is considered, the study findings indicate that only lobectomy (not limited resection) had an impact on QoL from before to after surgery. In fact, there was a significant decrease in physical health QoL and an improvement in mental health QoL from pre-surgery to follow-up in the lobectomy group. The multivariate analysis confirmed that physical health QoL was lower at followup (compared with before surgery) among patients who underwent lobectomy, but no change in physical health QoL was observed among those who underwent limited resection. It is possible that the more invasive nature of lobectomy in comparison to sublobectomy is partially responsible for the observed differences in QoL after surgery. Lobectomy is associated with more complications and longer hospital stay in comparison to sublobectomy. ${ }^{56,57}$ The modest improvement in mental health QoL that was seen in univariate analysis is difficult to explain given the greater potential for complications and longer hospital stays associated with lobectomy, ${ }^{58,59}$ but perhaps it reflects a sense of release or decreased anxiety associated with the removal of a more advanced tumor that required lobectomy. The mental health QoL result, however, should be interpreted with caution as the finding was no longer statistically significant in the multivariate analysis.

The study has a number of limitations. The small sample size may have made it less likely to detect significant differences. It is possible that some of the borderline significant results, such as the multivariate finding regarding the lower mental health QoL at follow-up among women compared with men would have been statistically significant had the sample size been larger. Although we limited the analysis to the main a priori hypotheses that $\mathrm{QoL}$ varied according to type of surgery and sex, the results must be taken as preliminary, because there is the possibility of chance findings due to multiple comparisons in a small sample of participants. Further, it is difficult to know whether the decreased physical health QoL would persist in the long term as the current study used a window of 7-18 months after surgery for inclusion in the study. This study is not consistent with some of the literature on surgery for advanced lung cancer, reporting that physical QoL goes back to baseline or even exceeds baseline levels 3-9 months after surgery. It has to be noted that these studies used different indicators of physical QoL including a pulmonary function test, and this may account for some of the differences. ${ }^{37,38}$ The SF-12 is a general measure of QoL, not specific to cancer or lung cancer; as a result it is inferior to other diseaseoriented questionnaire in use to assess QoL in cancer survivors, and is more susceptible to floor and ceiling effects. However, the current study findings may be consistent with other studies that have found that decreased physical QoL persists in the long term. ${ }^{2,32-36}$ Future prospective longitudinal research will help to delineate the chronicity of these effects on QoL. Finally, the results presented in the current study are preliminary in nature and, although the physical component of QoL changed in a statistically significant manner, those results may not translate into clinical relevance. A change of 2-3 points on the SF-12 may result in only a minimal experience of improved or worsened QoL if at all. Future research with larger sample sizes and more specific QoL measurement may help to better differentiate the scores leading to greater clinical significance.

The current study findings have implications for surgeons and other lung cancer health care professionals regarding how to most effectively present the possible impacts (or non-impacts) of surgery on the quality of life to this sub- 
set of patients in which disease has not yet significantly progressed. The physical health QoL negative impact has to be carefully explained, with special attention given to issues specific to women's QoL as women may be at higher risk for negative $\mathrm{QoL}$ consequences of surgery. The potential improvement in mental health QoL after surgery, perhaps resulting from decreased anxiety among other factors, is also something that lung cancer health care professionals can point to regarding one of the less obvious potential positive consequences of undergoing surgery at an early stage.

Given the numerous surgical options that are sometimes available when lung cancer is detected at such an early stage, it is also helpful for patients to understand the potential impacts of the various types of surgery on their overall QoL as well as their mental and physical health QoL. Perhaps particular attention should be paid to the post-surgical functioning of patients who underwent lobectomy as these patients may experience more of the negative physical health QoL impact, but ultimately seem to have a more positive mental health QoL impact compared with patients who underwent limited resection. This research adds new information to the body of literature that will assist in guiding surgeons and other lung cancer health care professionals in their discussions and their decisions regarding surgery for early-stage lung cancer patients. Although clinicians treating this group of patients may view their patients as "cured" after surgical resection, the present results highlight that there may be post-surgical quality of life issues that require ongoing attention. Future research should focus on examining these issues with larger numbers of early-stage lung cancer patients and conducting longer term follow-up (perhaps 5-10 years after surgery) assessments to determine what $\mathrm{QoL}$ impacts are persistent over time.

\section{I-ELCAP investigators}

Mount Sinai School of Medicine, New York, NY: Claudia I Henschke, Principal Investigator, David F Yankelevitz, Rowena Yip, Dongming $\mathrm{Xu}$, Mary Salvatore, Raja Flores, Andrea Wolf; Weill Cornell Medical College: Dorothy I McCauley, Mildred Chen, Daniel M Libby, James P Smith, Mark Pasmantier; Nasser Altorki; Cornell University: AP Reeves; CBNS, City University of New York at Queens College, Queens, NY; Steven Markowitz, Albert Miller; Fundacion Instituto Valenciano de Oncologia, Valencia, Spain: Jose Cervera Deval; University of Toronto, Princess Margaret Hospital, Toronto, Canada: Heidi Roberts, Demetris Patsios; Azumi General Hospital, Nagano, Japan: Shusuke Sone, Takaomi Hanaoka; Clinica Universitaria de Navarra, Pamplona, Spain: Javier Zulueta, Juan de Torres, Maria D Lozano; Swedish
Medical Center, Seattle, WA: Ralph Aye, Kristin Manning; Christiana Care, Helen F Graham Cancer Center, Newark, DE: Thomas Bauer; National Cancer Institute Regina Elena, Rome, Italy: Stefano Canitano, Salvatore Giunta; St Agnes Cancer Center, Baltimore, MD: Enser Cole; LungenZentrum Hirslanden, Zurich, Switzerland: Karl Klingler; Columbia University Medical Center, New York, NY: John HM Austin, Gregory DN Pearson; Hadassah Medical Organization, Jerusalem, Israel: Dorith Shaham; Holy Cross Hospital Cancer Institute, Silver Spring, MD: Cheryl Aylesworth; Nebraska Methodist Hospital, Omaha, NE: Patrick Meyers; South Nassau Communities Hospital, Long Island, NY: Shahriyour Andaz; Eisenhower Lucy Curci Cancer Center, Rancho Mirage, CA; Davood Vafai; New York University Medical Center, New York, NY: David Naidich, Georgeann McGuinness; Dorothy E Schneider Cancer Center, Mills-Peninsula Health Services, San Mateo, CA: Barry Sheppard; State University of New York at Stony Brook, Stony Brook, NY: Matthew Rifkin; ProHealth Care Regional Cancer Center, Waukesha \& Oconomowoc Memorial Hospitals, Oconomowoc, WI: M Kristin Thorsen, Richard Hansen; Maimonides Medical Center, Brooklyn, NY: Samuel Kopel; Wellstar Health System, Marietta GA: William Mayfield; St Joseph Health Center, St Charles, MO: Dan Luedke; Roswell Park Cancer Institute, Buffalo, NY: Donald Klippenstein, Alan Litwin, Peter A Loud; Upstate Medical Center, Syracuse, NY: Leslie J Kohman, Ernest M Scalzetti; Jackson Memorial Hospital, University of Miami, Miami, FL; Richard Thurer, Nestor Villazamar; State University of New York, North Shore-Long Island Jewish Health System, New Hyde Park, NY: Arfa Khan, Rakesh Shah; The $5^{\text {th }}$ Affiliated Hospital of Sun Yat-Sen University, Zhuhai, China: Xueguo Liu; Mercy Medical Center, Rockville Center, NY: Gary Herzog; Shin Kong Wu Ho-Su Memorial Hospital, Taipei, Taiwan: Diana Yeh; National Cancer Institute of China, Beijing, China: Ning Wu; Staten Island University Hospital, Staten Island NY: Joseph Lowry, Mary Salvatore; Central Main Medical Center: Carmine Frumiento; Mount Sinai School of Medicine, New York, NY: David S Mendelson; Georgia Institute for Lung Cancer Research, Atlanta, GA: Michael V Smith; The Valley Hospital Cancer Center, Paramus NJ: Robert Korst; Health Group Physimed/McGill University, Montreal, CA Jana Taylor; Memorial Sloan-Kettering Cancer Center, New York, NY: Michelle S Ginsberg; John Muir Cancer Institute, Concord CA: Michaela Straznicka; Atlantic Health Morristown Memorial Hospital, Morristown NJ: Mark Widmann; Alta Bates Summit Medical Center, Berkeley CA: Gary Cecchi; New York Medical College, Valhalla, NY: Terence AS Matalon; St Joseph's Hospital, Atlanta GA: Paul Scheinberg; Mount Sinai Comprehensive Cancer Center, Miami Beach, FL: Shari-Lynn Odzer; Aurora St Luke's Medical Center, Milwaukee WI: David Olsen; City of Hope National Medical Center, Duarte, CA: Fred Grannis, Arnold Rotter; Evanston Northwestern Healthcare Medical Group, Evanston, IL: Daniel Ray; Greenwich Hospital, Greenwich, CT: David Mullen; Our Lady of Mercy Medical Center, Bronx, NY: Peter H Wiernik; Baylor University Medical Center, Dallas TX: Edson H Cheung; Sequoia Hospital, Redwood City CA: Melissa Lim; Glens Falls Hospital, Glens Falls NY: Louis DeCunzo; Atlantic Medical Imaging, Atlantic City NJ: Robert Glassberg; Karmanos Cancer Institute, Detroit, MI: Harvey Pass, Carmen Endress; Rush University, Chicago IL: Mark Yoder, Palmi Shah; Building Trades, Oak Ridge TN: Laura Welch; Sharp Memorial Hospital, San Diego, CA: Michael Kalafer; Newark Beth Israel Medical Center, Newark NJ Jeremy Green; Guthrie Cancer Center, Sayre PA: James Walsh, David Bertsch; Comprehensive Cancer Centers of the Desert, Palm Springs CA: Elmer Camacho; Dickstein Cancer Treatment Center, White Plains Hospital, White Plains NY: Cynthia Chin; Presbyterian Healthcare, Charlotte NC: James O’Brien; University of Toledo, Toledo OH: James C Willey 


\section{References}

1. Gilbert SM, Miller DC, Hollenbeck BK, Montie JE, Wei JT. Cancer survivorship: challenges and changing paradigms. J Urol. 2008;179:431-438

2. Sarna L, Padilla G, Holmes C, Tashkin D, Brecht ML, Evangelista L. Quality of life of long-term survivors of non-small-cell lung cancer. J Clin Oncol. 2002;20:2920-2929.

3. Siddiqui F, Konski AA, Movsas B. Quality-of-life concerns in lung cancer patients. Expert Rev Pharmacoecon Outcomes Res. 2010;10:667-676.

4. Cella DF. Measuring quality of life in palliative care. Semin Oncol. 1995;22(2 Suppl 3):73-81.

5. Schipper H, Clinch J, Olweny CLM. Quality of life studies: definitions and conceptual issues. In: Spilker B, ed. Quality of Life and Pharmacoeconomics in Clinical Trials. Philadelphia: LippincottRaven Publishers; 1996:11-23.

6. Schipper H, Clinch J, Olweny C. Quality of life studies: definitions and conceptual issues. In: Spilker B, ed. Quality of Life and Pharmacoeconomics in Clinical Trials. Philadelphia: LippincottRaven Publishers; 1996:11-23.

7. Pearman T. Psychosocial factors in lung cancer: quality of life, economic impact, and survivorship implications. J Psychosoc Oncol. 2008;26:69-80.

8. Grant M, Economou D, Ferrell BR. Oncology nurse participation in survivorship care. Clin J Oncol Nurs. 2010;14:709-715.

9. Le Corroller-Soriano AG, Bouhnik AD, Preau M, et al. Does cancer survivors' health-related quality of life depend on cancer type? Findings from a large French national sample 2 years after cancer diagnosis. Eur J Cancer Care. 2011;20:132-140.

10. Akin S, Can G, Aydiner A, Ozdilli K, Durna Z. Quality of life, symptom experience and distress of lung cancer patients undergoing chemotherapy. Eur J Oncol Nurs. 2010;14:400-409.

11. Buzaglo J, Gayer C, Mallick R, et al. Understanding the experience of living with non-small-cell lung cancer (NSCLC): a qualitative study. J Comm Support Oncology. 2014;12:6-12.

12. Lehto RH. Identifying primary concerns in patients newly diagnosed with lung cancer. Oncol Nurs Forum. 2011;38:440-447.

13. Pozo CL, Morgan MA, Gray JE. Survivorship issues for patients with lung cancer. Cancer Control. 2014;21:40-50.

14. Lee LJ, Chung CW, Chang YY, et al. Comparison of the quality of life between patients with non-small-cell lung cancer and healthy controls. Qual Life Res. 2011;20:415-423.

15. Sanders SL, Bantum EO, Owen JE, Thornton AA, Stanton AL. Supportive care needs in patients with lung cancer. Psychooncology. 2010;19:480-489.

16. Damhuis RA, Schutte PR. Resection rates and postoperative mortality in 7,899 patients with lung cancer. Eur Resp J. 1996;9:7-10.

17. Pompili C. Quality of life after lung resection for lung cancer. J Thorac Dis. 2015;7(suppl 2):S138-144.

18. Anant M, Guleria R, Pathak AK, et al. Quality of life measures in lung cancer. Indian J Cancer. 2005;42:125-132.

19. Langendijk H, Aaronson NK, de Jong JM, ten Velde GP, Muller MJ, Wouters M. The prognostic impact of quality of life assessed with the EORTC QLQ-C30 in inoperable non-small cell lung carcinoma treated with radiotherapy. Radiother Oncol. 2000;55:19-25

20. Montazeri A, Milroy R, Hole D, McEwen J, Gillis CR. Quality of life in lung cancer patients: as an important prognostic factor. Lung Cancer. 2001;31:233-240.

21. Efficace F, Bottomley A, Smit EF, et al. Is a patient's self-reported health-related quality of life a prognostic factor for survival in non-small-cell lung cancer patients? A multivariate analysis of prognostic factors of EORTC study 08975. Ann Oncol. 2006;17:1698-1704

22. Ganz PA, Lee JJ, Siau J. Quality of life assessment. An independent prognostic variable for survival in lung cancer. Cancer. 1991;67:3131-3135.

23. Herndon JE, 2nd, Fleishman S, Kornblith AB, Kosty M, Green MR, Holland J. Is quality of life predictive of the survival of patients with advanced nonsmall cell lung carcinoma? Cancer. 1999;85:333-340.
24. Brown J, Thorpe H, Napp V, et al. Assessment of quality of life in the supportive care setting of the big lung trial in non-small-cell lung cancer. J Clin Oncol. 2005;23:7417-7427.

25. Maione P, Perrone F, Gallo C, et al. Pretreatment quality of life and functional status assessment significantly predict survival of elderly patients with advanced non-small-cell lung cancer receiving chemotherapy: a prognostic analysis of the multicenter Italian lung cancer in the elderly study. J Clin Oncol. 2005;23:6865-6872.

26. Moller A, Sartipy U. Associations between changes in quality of life and survival after lung cancer surgery. J Thorac Oncol. 2012;7:183-187.

27. Ostroff JS, Krebs P, Coups EJ, et al. Health-related quality of life among early-stage, non-small cell, lung cancer survivors. Lung Cancer. 2011;71:103-108.

28. Rauma V, Sintonen H, Rasanen JV, Salo JA, Ilonen IK. Long-term lung cancer survivors have permanently decreased quality of life after surgery. Clinic Lung Cancer. 2015;16:40-45.

29. Fernando HC, Landreneau RJ, Mandrekar SJ, et al. Analysis of longitudinal quality-of-life data in high-risk operable patients with lung cancer: results from the ACOSOG Z4032 (Alliance) multicenter randomized trial. J Thorac Cardiovasc Surg. 2015;149:718725; discussion 725-716.

30. Lagerwaard FJ, Aaronson NK, Gundy CM, Hassbeek CJ, Slotman BJ, Senan S. Patient-reported quality of life after stereotactic ablative radiotherapy for early-stage lung cancer. J Thorac Oncol. 2012;7:1148-1154

31. Koczywas M, Williams AC, Cristea M, et al. Longitudinal changes in function, symptom burden, and quality of life in patients with early-stage lung cancer. Ann Surg Oncol. 2013;20:1788-1797.

32. Schulte T, Schniewind B, Dohrmann P, Kuchler T, Kurdow R. The extent of lung parenchyma resection significantly impacts longterm quality of life in patients with non-small cell lung cancer. Chest. 2009;135:322-329.

33. Moller A, Sartipy U. Long-term health-related quality of life following surgery for lung cancer. Eur J Cardio-Thorac Surgery. 2012;41:362-367.

34. Schulte T, Schniewind B, Walter J, Dohrmann P, Kuchler T, Kurdow R. Age-related impairment of quality of life after lung resection for non-small cell lung cancer. Lung Cancer. 2010;68:115-120.

35. Ilonen IK, Rasanen JV, Knuuttila A, et al. Quality of life following lobectomy or bilobectomy for non-small cell lung cancer, a twoyear prospective follow-up study. Lung Cancer. 2010;70:347-351.

36. Kenny PM, King MT, Viney RC, et al. Quality of life and survival in the 2 years after surgery for non-small-cell lung cancer. J Clin Oncol. 2008;26:233-241.

37. Dales RE, Belanger R, Shamji FM, Leech J, Crepeau A, Sachs HJ. Quality-of-life following thoracotomy for lung cancer. J Clin Epidemiol. 1994;47:1443-1449.

38. Zieren HU, Muller JM, Hamberger U, Pichlmaier H. Quality of life after surgical therapy of bronchogenic carcinoma. Eur J Cardiothorac Surgery. 1996;10:233-237.

39. Xie D, Deschamps C, Shen RK, et al. Bilobectomy versus lobectomy for non-small cell lung cancer: a comparative study of outcomes, long-term survival, and quality of life. Ann Thorac Surg. 2015;100:242-250

40. Kim SK, Young HA, Yoon JA, et al. Efficacy of systemic postoperative pulmonary rehabilitation after lung resection surgery. Ann Rehabil Med. 2015;39:366-373.

41. Raz DJ, Sun V, Kim JY, et al. Long-term effect of an interdisciplinary supportive care intervention for lung cancer survivors after surgical procedures. Ann Thorac Surg. 2015;In Press:1-9. doi: 10.1016/j.athoracsur.2015.07.031.

42. Siegel R, DeSantis C, Virgo K, et al. Cancer treatment and survivorship statistics, 2012. CA Cancer J Clin. 2012;62:220-241.

43. Cavalheri V, Jenkins $S$, Cecins $N$, et al. Impairments after curative intent treatment for non-small cell lung cancer: a comparison with age and gender-matched health controls. Respir Med. 2015;109:1332-1339.

44. Chang NW, Lin KC, Hsu WH, Lee SC, Chan JYH, Wang KY. 
The effect of gender on health-related quality of life and related factors in post-lobectomy lung-cancer patients. Eur J Oncol Nurs. 2015;19:292-300.

45. Louie AV, Rodrigues G, Hannouf M, et al. Stereotactic body radiotherapy versus surgery for medically operable stage I nonsmall-cell lung cancer: a Markov model-based decision analysis. Int J Radiat Oncol Biol Phys. 2011;81:964-973.

46. Ochroch EA, Gottschalk A, Augostides J, et al. Long-term pain and activity during recovery from major thoracotomy using thoracic epidural analgesia. Anesthesiology. 2002;97:1234-1244.

47. Sterzi S, Cesario A, Cusumano G, et al. How best to assess the quality of life in long-term survivors after surgery for NSCLC? Comparison between clinical predictors and questionnaire scores. Clin Lung Cancer. 2013;14:78-87.

48. Park S, Kang CH, Hwang $\mathrm{Y}$, et al. Risk factors for postoperative anxiety and depression after surgical treatment for lung cancer. Eur J Cardiothorac Surg. Published online September 26, 2015. doi: 10.1093/ejcts/ezv336.

49. Hencshke CI. International Early Lung Cancer Action Program: Enrollment and Screening Protocol. 2014. http://www.ielcap. org/sites/default/files/I-ELCAP\%20protocol-v21-3-1-14.pdf. Accessed August 14, 2015.

50. Ware J Jr, Kosinski M, Keller SD. A 12-item short-form health survey: construction of scale and preliminary tests of reliability and validity . Medical Care. 1996;34:220-233.

51. Poitras S, Beaule PE, Dervin GF. Validity of a short-term quality of life questionnaire in patients undergoing joint replacement: the quality of recovery-40. J Arthroplasty. 2012;27:1604-1608.
52. Godil SS, Parker SL, Zuckerman SL, Mendenhall SK, Glassman $\mathrm{SD}, \mathrm{McGirt} \mathrm{MJ}$. Accurately measuring the quality and effectiveness of lumbar surgery in registry efforts: determining the most valid and responsive instruments. Spine J. 2014;14:2885-2891.

53. Poghosyan H, Stock S, Kennedy Sheldon L, Cromwell J, Cooley ME, Nerenz DR. Racial disparities in health-related quality of life after lung cancer surgery: findings from the cancer care outcomes research and surveillance consortium. J Thorac Oncol. 2015;10:1404-1412.

54. Krouse RS, Herrinton LJ, Grant M, et al. Health-related quality of life among long-term rectal cancer survivors with ostomy: manifestations by sex. J Clin Oncol. 2009;27:4664-4670.

55. Schmidt CE, Bestmann B, Küchler T, Longo WE, Rohde $\mathrm{V}$, Kremer B. Gender differences in quality of life of patients with rectal cancer. A five-year prospective study. World J Surg. 2005;29:1630-1641.

56. El-Sherif A, Gooding WE, Santos R, et al. Outcomes of sublobar resection versus lobectomy for stage I non-small cell lung cancer: a 13-year analysis. Ann Thorac Surg. 2006;82:408-415.

57. Koike T, Yamato Y, Yoshiya K, Shimoyama T, Suzuki R. Intentional limited pulmonary resection for peripheral T1 N0 M0 small-sized lung cancer. J Thorac Cardiovasc Surg. 2003;125:924-928.

58. Altorki N, Kohman LJ, Veit LJ, You YN, Boughey JC. Limited resection as a cure for early lung cancer: time to challenge the gold standard? Bull Am Col Surg. 2015;100:57-58.

59. Altorki N, Yip R, Hanaoka T, et al. Sublobar resection is equivalent to lobectomy for clinical stage $1 \mathrm{~A}$ lung cancer in solid nodules. J Thorac Cardiovasc Surg. 2014;147:754-762. 